\title{
Perbandingan Model Cox Proportional Hazard dan Regresi Weibull untuk Menganalisis Ketahanan Bank Syariah
}

\author{
Yusrillah Ihza Zianita Afni ${ }^{1}$, Mohamad Fatekurohman ${ }^{2}$, dan Dian Anggraeni ${ }^{3}$ \\ 1,2,3 Jurusan Matematika, Fakultas Matematika dan Ilmu Pengetahuan Alam, Universitas Jember
}

rereafni1996@gmail.com,mfatekurohman.fmipa@unej.ac.id

\begin{abstract}
On July 1, 2014 Financial Services Authority (OJK) issued a new regulation number 8/PJOK.13/2014 concerning the health of general sharia banks that can be valued from several aspects including credit risk, liquidity risk, Return on Asset (ROA), Net of Margin (NOM) and Capital Adequacy Ratio (CAR). The purpose of this study is to compare the models of Cox proportional hazard and Weibull regression for the resistance of sharia bank in 2017-2018 for 24 data. The data were analyzed by describing each variable and modeling in each method. Comparison result shows that Weibull regression model is better than the Cox proportional hazard model because it has smaller AIC and MSE.
\end{abstract}

Keywords : Sharia Bank, Survival Analysis, AIC, MSE

\section{Pendahuluan}

Sesuai dengan UU No.21 tahun 2008, bank syariah adalah bank yang menjalankan segala kegiatannya berdasarkan syariah. Pada tanggal 1 Juli 2014, Otoritas Jasa Keuangan (OJK) mengeluarkan peraturan baru nomor 8/POJK.13/2014 yang menyatakan tentang kesehatan bank syariah umum dapat dinilai dari beberapa aspek diantaranya risk profile, good corporate governance, earning dan capital [1].

Data menunjukkan nasabah bank syariah di Indonesia jumlahnya tidak sebanyak dengan nasabah bank konvensional, hal tersebut sesuai dengan grafik rasio likuiditas, rasio capital dan rasio asset pada bank syariah menunjukkan lebih rendah dari bank konvensional. Berdasarkan hal tersebut peneliti tertarik untuk melakukan penelitian terhadap katahanan bank syariah. Faktor-faktor tentang kesehatan bank syariah menurut OJK akan dijadikan sebagai variabel independen dan dianalisis menggunakan metode statistik. Adapun metode statistika yang digunakan untuk menganalisis dalam bidang terapan yaitu analisis survival (survival analysis) atau analisis kelangsungan hidup. Analisis ini biasanya digunakan dalam menduga probabilitas kelangsungan hidup, kekambuhan suatu penyakit, kematian dan peristiwa-peristiwa lainnya sampai pada periode waktu tertentu. Analisis survival salah satunya akan digunakan untuk menganalisis ketahanan pada suatu bank syariah [2]. Hal yang terpenting dalam analisis survival adalah memodelkan waktu kegagalan yang memiliki korelasi dengan variabel independen. 
Penelitian tentang penerapan analisis survival di bidang ekonomi yaitu "hubungan antara financial distress dan keputusan kebijakan dividen omisi" [3]. Penelitian tersebut mengambil faktor-faktor dari kebijakan dividen omisi yang digunakan sebagai prediktor. Metode yang digunakan pada yaitu metode Cox proportional hazard. Penelitian lain di bidang kesehatan, yaitu tentang "Analisis ketahanan pasien kanker paru menggunakan regresi Weibull" [4]. Penelitian tersebut menggunakan prediktor dari faktor faktor yang memepengaruhi kanker paru dengan menggunakan metode regresi Weibull. Oleh sebab itu, penelitian ini menggunakan kasus yang berbeda yaitu bidang keuangan (perbankan). Metode yang digunakan yaitu metode perbandingan antara Cox proportional hazard dan regresi Weibull berdasarkan nilai Akaike's Information Criterion (AIC) dan Mean Squared Error (MSE) yang lebih kecil. Penelitian ini bertujuan menentukan perbandingan model terbaik dari ketahanan bank syariah. Hal tersebut dapat memberikan informasi kepada pihak bank tentang bagaimana ketahanan bank syariah yang sedang terjadi supaya dapat melakukan tindakan yang membuat ketahanan bank syariah menjadi stabil.

\section{Metode Penelitian}

Perbandingan metode yang digunakan untuk penelitian ini yaitu metode Cox proportional hazard dan metode regresi Weibull.

2.1. Pemodelan Cox Proportional Hazard. Konsep dasar pemodelan Cox proportional hazard yaitu semua variabel harus memenuhi asumsi proportional hazard. Model Cox proportional hazard memiliki asumsi yang menyatakan bahwa rasio dari fungsi hazard dua individu yang berlainan adalah konstan [5], sehingga diperoleh model regresi Cox:

$$
h(t, x)=h_{0}(t) \exp \left(\beta_{1} x_{1}+\beta_{2} x_{2}+\ldots+\beta_{p} x_{p}\right)
$$

dengan

$h(t, x) \quad$ : resiko kegagalan individu pada waktu $t$ dengan karakteristik $x$

$h_{0}(t) \quad$ : fungsi dasar hazard,

$\beta_{1}, \beta_{2}, \ldots, \beta_{p} \quad$ : parameter regresi,

$x_{1}, x_{2}, \ldots, x_{p} \quad$ : nilai dari variabel bebas $X_{1}, X_{2}, \ldots, X_{p}$. 
2.2. $\quad$ Pemodelan Regresi Weibull. Distribusi Weibull merupakan salah satu distribusi kontinu yang banyak digunakan dalam pemodelan analisis kelangsungan hidup. Misal $T$ adalah waktu survival dan $T$ berdistribusi Weibull, maka $T$ merupakan suatu variabel random positif, dengan parameter $\gamma>0$ dan $\beta>0$, jika fungsi kepadatan peluangnya diberikan oleh

$$
f(t)=\left\{\begin{array}{cl}
\frac{\gamma}{\lambda}\left(\frac{t}{\lambda}\right)^{\gamma-1} e^{-\left(\frac{t}{\lambda}\right)^{\gamma}} & , t<0 \\
0 & , \text { lainnya. }
\end{array}\right.
$$

Akaike's Information Criterion (AIC) adalah metode yang berguna untuk mendapatkan model terbaik yang ditemukan oleh Akaike. Nilai AIC dapat dilihat pada persamaan

$$
A I C=-2 l(\beta)+2 d f
$$

dengan $l(\beta)$ adalah fungsi loglikelihood dan $d f$ adalah derajat bebas yang digunakan dalam model. Model regresi ataupun distribusi terbaik adalah model regresi yang memiliki nilai AIC terkecil [6].

Data yang digunakan dalam penelitian ini merupakan data sekunder, yaitu data laporan bulanan Bank Syariah Mandiri selama 24 bulan pada tahun 2017-2018. Terdapat 5 variabel bebas untuk membentuk model terbaik dari ketahanan bank syariah, yaitu Resiko Kredit $\left(X_{1}\right)$, Resiko Likuiditas $\left(X_{2}\right)$, ROA $\left(X_{3}\right)$, NOM $\left(X_{4}\right)$, Capital $\left(X_{5}\right)$. Penelitian ini menggunakan program aplikasi olah data $\mathrm{R}$ versi 3.4.3. Langkah-langkah yang dilakukan dalam penelitian yaitu mengumpulkan data sekunder kemudian melakukan analisis deskriptif pada masing-masing variabel serta melakukan uji Kaplan-Meier dan uji log-rank. Pemodelan Cox proportional hazard yang pertama dilakukan yaitu uji asumsi proportional hazard dengan uji GOF dan melakukan estimasi dari model Cox proportional hazard hingga mendapatkan model. Pemodelan regresi Weibull diawali dengan uji kesesuaian distribusi dan uji multikolinieritas, kemudian estimasi model regresi Weibull hingga mendapatkan model. Perbandingan kedua model berdasarkan nilai AIC dan MSE yang lebih kecil. 


\section{Hasil dan Pembahasan}

3.1 Analisis Deskriptif. Berdasarkan data laporan keuangan bulanan dapat dilihat pada Lampiran A sebanyak 24, seperti pada Tabel 1, untuk variabel resiko kredit terdapat 16 data memiliki status tidak aman dan 9 data aman. Variabel lain seperti resiko likuiditas, ROA, NOM, CAR semua data berstatus aman. Setiap variabel memiliki batas aman dan tidak terhadap ketahanan bank syariah yaitu berdasarkan dengan Peraturan OJK Nomor 08/POJK.03/2014. Nilai rata-rata dari rasio kredit diperoleh sebesar 4,78\%. Hal terebut berarti bahwa rasio resiko kredit memilki rata-rata di bawah batas aman. Rasio dari resiko likuiditas, ROA, NOM dan CAR memberikan nilai mean di atas batas aman.

Tabel 1. Analisis deskriptif

\begin{tabular}{|c|c|c|c|c|c|c|}
\hline \multirow{2}{*}{ Prediktor } & \multirow{2}{*}{ Kategori } & \multirow{2}{*}{ Jumlah } & \multicolumn{2}{|c|}{ Status } & \multirow{2}{*}{$\begin{array}{c}\text { Mean } \\
(\%)\end{array}$} & \multirow{2}{*}{$\begin{array}{c}\text { Median } \\
(\%)\end{array}$} \\
\hline & & & Aman & Tidak & & \\
\hline Resiko kredit & $\begin{array}{l}>5 \% \\
<5 \%\end{array}$ & 24 & 8 & 16 & 4,78 & 4,20 \\
\hline Resiko likuiditas & $\begin{array}{l}>0 \% \\
<0 \%\end{array}$ & 24 & 24 & 0 & 26,70 & 26,00 \\
\hline ROA & $\begin{array}{l}>0 \% \\
<0 \%\end{array}$ & 24 & 24 & 0 & 5,071 & 5,00 \\
\hline NOM & $\begin{array}{l}>2 \% \\
<2 \%\end{array}$ & 24 & 24 & 0 & 6,179 & 6,100 \\
\hline CAR & $\begin{array}{l}>8,00 \% \\
<8,00 \%\end{array}$ & 24 & 24 & 0 & 14,95 & 15,00 \\
\hline
\end{tabular}

3.2 Uji Kaplan-Meier dan Log-Rank. Analisis Kaplan-Meier digunakan untuk mengestimasi fungsi tahan hidup dan mengetahui karakteristik kurva tahan hidup. Kurva tahan hidup Kaplan-Meier digunakan untuk menggambarkan peluang ketahanan bank syariah berdasarkan variabel bebas. Gambar 1 merupakan gambaran karakteristik waktu ketahanan bank syariah secara umum. Dapat dilihat bahwa kurva ketahanan bank syariah turun cepat pada waktu $t=30$ sampai dengan $t=31$. Hal tersebut menunjukkan bahwa 
peluang ketahanan bank syariah semakin memburuk. Setelah mengetahui kurva KaplanMeier secara keseluruhan, selanjutnya dilakukan uji log-rank untuk mengetahui ada tidaknya perbedaan antar kurva ketahanan Kaplan-Meier dalam variabel yang berbeda.

Pada umumnya penelitian dalam bidang keuangan membutuhkan tingkat ketelitian yang tinggi sehingga menghasilkan sedikit kesalahan, oleh karena itu penelitian ini menggunakan taraf signifikansi sebesar 0,01. Berdasarkan Tabel 2 dapat diperoleh bahwa $p$-value > 0,01 untuk semua variabel yaitu resiko kredit, resiko likuiditas, ROA, NOM dan CAR. Artinya didapatkan bahwa pada variabel tersebut tidak ada perbedaan antara kurva ketahanan bank syariah yang memiliki peluang ketahanan cenderung sama untuk masing masing kategori.

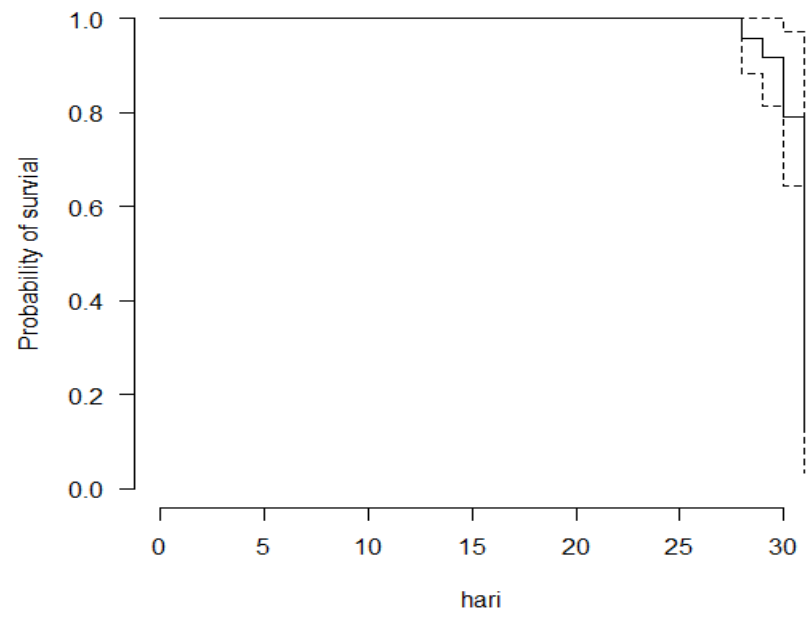

Gambar 1. Kurva ketahanan bank syariah

Tabel 2. Uji log-rank

\begin{tabular}{lccc}
\hline \multicolumn{1}{c}{ Variabel } & Log-rank & Derajat bebas & $p$-value \\
\hline Resiko kredit & 11 & 14 & 0,09 \\
Resiko likuiditas & 26,4 & 15 & 0,7 \\
ROA & 16,1 & 9 & 0,06 \\
NOM & 19,7 & 16 & 0,09 \\
CAR & 21 & 16 & 0,06 \\
\hline
\end{tabular}


Tabel 3. Pengujian asumsi proportional hazard dengan GOF

\begin{tabular}{lcc}
\hline \multicolumn{1}{c}{ Variabel } & p-value & Keputusan \\
\hline Resiko kredit & 0,874 & Gagal tolak $H_{0}$ \\
Resiko Likuiditas & 0,345 & Gagal tolak $H_{0}$ \\
ROA & 0,616 & Gagal tolak $H_{0}$ \\
NOM & 0,664 & Gagal tolak $H_{0}$ \\
CAR & 0,271 & Gagal tolak $H_{0}$ \\
\hline
\end{tabular}

3.3 Pemodelan Cox Proportional Hazard. Berdasarkan hasil uji GOF pada Tabel 3 didapatkan bahwa nilai p-value variabel resiko kredit, resiko likuiditas, ROA, NOM, CAR $>0,05$ maka diperoleh keputusan gagal menolak $H_{0}$ untuk semua variable, sehingga dapat disimpulkan bahwa semua variabel memenuhi asumsi proportional hazard. Berdasarkan Tabel 4 diperoleh model Cox proportional hazard

$$
h(t, x)=h_{0}(t) \exp \left(-0,6210 X_{1}-0,1204 X_{2}+0,2179 X_{3}+0,2823 X_{4}-0,0074 X_{5}\right)
$$

Uji signifikansi parameter dilakukan dengan dua cara, yaitu uji serentak dan parsial. Uji serentak Pada Tabel 4 diperoleh nilai p-value likelihood ratio sebesar 0,2. Nilai tersebut lebih dari nilai $\alpha=0,05$ sehingga menghasilkan keputusan gagal menolak $H_{0}$, artinya tidak ada satu variabel independen yang berpengaruh terhadap model. Selain melakukan uji serentak juga dilakukan uji parsial. Berdasarkan Tabel 4 didapatkan $p$ value untuk semua variabel bebas lebih dari 0,05 . Hal ini menunjukkan gagal menolak $H_{0}$, artinya tidak ada variabel independen yang berpengaruh secara signifikan terhadap model. Dalam kasus ketahanan bank syariah berarti jika ada satu variabel bebas di bawah batas aman maka tidak akan mempengaruhi ketahanan bank syariah. Jika semua variabel di bawah batas aman maka akan mempengaruhi ketahanan bank syariah. 
Tabel 4. Estimasi Parameter Model Cox proportional hazard

\begin{tabular}{llccc}
\hline \multicolumn{1}{c}{ Variabel } & Koefisien & Hazard Ratio & Standard Error & p-value \\
\hline Resiko kredit & $-0,6210$ & 0,537394 & 0,34009 & 0,0678 \\
Resiko likuiditas & $-0,1204$ & 0,886552 & 0,15402 & 0,4344 \\
ROA & 0,217952 & 1,243528 & 0,37049 & 0,5563 \\
NOM & 0,2723 & 1,326204 & 0,22188 & 0,2032 \\
CAR & $-0,0074$ & 0,992582 & 0,24194 & 0,9755 \\
Likelihood ratio & & & & 0,2 \\
\hline
\end{tabular}

3.4 Pemodelan Regresi Weibull. Pengujian kesesuaian distribusi data menggunakan uji Kolmogorov-Smirnov diperoleh $\lambda=2,7678, \beta=5,1517$, nilai $p$-value $=0,89369$, dan $D_{\text {hit }}=0,11165$. Jika $D_{\text {tabel }}=0,20346$, maka berdasarkan hasil tersebut didapatkan bahwa $p$ value $>\alpha(0,01)$ atau $D_{\text {hit }}<D_{\text {tabel, }}$, sehingga gagal menolak $H_{0}$ yaitu data waktu ketahanan Bank Syariah Mandiri mengikuti distribusi Weibull.

\begin{tabular}{|c|c|c|c|c|c|}
\hline \multicolumn{6}{|c|}{ Weibull [ $\# 59]$} \\
\hline \multicolumn{6}{|c|}{ Kolmogorov-Smirnov } \\
\hline $\begin{array}{l}\text { Sample Size } \\
\text { Statistic } \\
\text { P-Value } \\
\text { Rank }\end{array}$ & $\begin{array}{l}24 \\
0,11165 \\
0,89369 \\
6\end{array}$ & & & & \\
\hline$\alpha$ & 0,2 & 0,1 & 0,05 & 0,02 & 0,01 \\
\hline Critical Value & 0,21205 & 0,24242 & 0,26931 & 0,30104 & 0,32286 \\
\hline
\end{tabular}

Gambar 2. Hasil uji Kolmogorov-Smirnov

Uji multikolinieritas dilakukan untuk mengetahui hubungan antar variabel pada data. Uji multikolinieritas pada data bank syariah dilakukan dengan uji Chi-Square. Hasil analisis uji Chi-Square yang dapat dilihat pada Tabel 5 menunjukkan bahwa $p$-value dari semua variabel lebih dari $\alpha(0,01)$. Hal tersebut memberikan arti bahwa hubungan antar variabel satu dengan lainya saling bebas, sehingga dilakukan pembentukan model regresi Weibull. 
Tabel 5. Nilai p-value uji Chi-Square

\begin{tabular}{lccccc}
\hline & $\mathrm{RK}\left(X_{1}\right)$ & $\mathrm{RL}\left(X_{2}\right)$ & $\mathrm{ROA}\left(X_{3}\right)$ & $\mathrm{NOM}\left(X_{4}\right)$ & $\mathrm{CAR}\left(X_{5}\right)$ \\
& & & & & \\
\hline $\mathrm{RK}\left(X_{1}\right)$ & 0 & 0,03373 & 0,1576 & 0,4517 & 0,2238 \\
$\mathrm{RL}\left(X_{2}\right)$ & 0,3373 & 0 & 0,2717 & 0,5536 & 0,04539 \\
$\operatorname{ROA}\left(X_{3}\right)$ & 0,1576 & 0,2717 & 0 & 0,5386 & 0,2667 \\
$\operatorname{NOM}\left(X_{4}\right)$ & 0,4517 & 0,5536 & 0,5386 & 0 & 0,262 \\
$\operatorname{CAR}\left(X_{5}\right)$ & 0,2238 & 0,04539 & 0,2667 & 0,262 & 0 \\
& & & & & \\
\hline
\end{tabular}

Tabel 6. Estimasi parameter regresi Weibull

\begin{tabular}{cccc}
\hline Variabel & Estimasi Parameter & Standard error & $p$-value \\
\hline Intercept $(\mu)$ & 3,368485 & 0,101599 & $<2 \times 10^{-16}$ \\
Resiko kredit & 0,011887 & 0,007074 & 0,093 \\
Resiko likuiditas & 0,002543 & 0,002744 & 0,354 \\
ROA & $-0,005236$ & 0,006661 & 0,432 \\
NOM & $-0,005325$ & 0,004095 & 0,193 \\
CAR & 0,000687 & 0,004224 & 0,871 \\
Scale $(\sigma)$ & 0,017 & & \\
& & & \\
\hline
\end{tabular}

Estimasi model regresi Weibull dilakukan menggunakan program R. Berdasarkan hasil Tabel 6 diperoleh model regresi Weibull :

$$
S(t \mid X)=\left\{\exp \left(3,368+0,0025 X_{1}-0,0025 X_{2}-0,0052 X_{3}+0,0053 X_{4}+0,00068 X_{5}\right)\right\}^{57,82}
$$

Uji signifikansi parameter pada regresi Weibull memberikan kesimpulan hasil yang sama dengan uji signifikansi Cox proportional hazard. 
3.5 Perbandingan Model. Perbandingan model Cox proportional hazard dan regresi Weibull dilakukan berdasarkan nilai AIC dan MSE. Model terbaik dipilih dengan cara melihat nilai AIC dan MSE yang lebih kecil.

Tabel 7. Perbandingan nilai AIC dan MSE

\begin{tabular}{ccc}
\hline Model & Nilai AIC & Nilai MSE \\
\hline Cox proportional hazard & 86,21024 & 0,006294 \\
Regresi Weibull & 51,12613 & 0,0000271 \\
\hline
\end{tabular}

Berdasarkan Tabel 7 diperoleh nilai AIC regresi Weibull lebih kecil dari pada nilai AIC Cox proportional hazard. Selain nilai AIC, perbandingan kedua model didasarkan pada nilai MSE. Hasil Tabel 7 menunjukan bahwa nilai MSE regresi Weibull lebih kecil dari pada nilai MSE Cox proportional hazard, sehingga dapat disimpulkan bahwa regresi Weibull merupakan model yang baik untuk menganalisis ketahanan bank syariah.

\section{Kesimpulan}

Hasil Perbandingan model Cox proportional hazard dan regresi Weibull untuk analisis ketahanan bank syariah menunjukan bahwa model Regresi Weibull lebih baik karena nilai AIC dan nilai MSE lebih kecil, dengan modelnya adalah

$$
S(t \mid X)=\left\{\exp \left(3,3680+0,0025 X_{1}-0,0025 X_{2}-0,0052 X_{3}+0,0053 X_{4}+0,00068 X_{5}\right)\right\}^{57,82}
$$

\section{Daftar Pustaka}

[1] Kasmir. Dasar-Dasar Bank. Jakarta: Raja Grafindo Persada. 2012.

[2] Lee, E. T dan Wang, J. W. Statistical Methods for Survival Data Analysis. Third Edition. New Jerses: John Wiley and Sons. 2002.

[3] Antika, D. P, Fatekurohman, M., dan Anggareani, D. Analisis hubungan antara Financial distress dan keputusan Deviden Omisi. Journal of Mathematics and Its Application, 41-54. 2018.

[4] Aviatus, S. dan Fatekurohman, M. Analisis ketahanan hidup pasien kanker paru menggunakan regresi Weibull. Indonesian Journal of Applied Statistics, 79-87. 2018.

[5] Kleinbaum, D. G. dan Klein, M. Survival Analisis a self-learning Text. Third Edition. New York: Springer. 2012.

[6] Fatturrahman, M. Pemilihan model regresi terbaik menggunakan metode akaike's information criterion dan schwart information criterion. Jurnal Informatika Mulawarman, 37-41. 2009. 
Lampiran A. Data laporan keuangan bulanan oleh PT Bank Syariah Mandiri, selama 24 bulan pada tahun 2017-2018

\begin{tabular}{|c|c|c|c|c|c|c|c|}
\hline Bulan/tahun & RK \% & RL \% & ROA \% & NOM \% & CAR \% & Status & Lama \\
\hline Januari/2017 & 4,5 & 27 & 5 & 6,5 & 13,7 & 0 & 31 \\
\hline Februari/2017 & 2 & 25 & 4 & 5 & 14 & 0 & 28 \\
\hline Maret/2017 & 4,9 & 27,9 & 6 & 6,9 & 13,9 & 0 & 31 \\
\hline April/2017 & 6 & 30 & 4 & 7 & 14,9 & 1 & 30 \\
\hline Mei/2017 & 4 & 32 & 6 & 8,5 & 15 & 0 & 31 \\
\hline Juni/2017 & 7 & 30 & 7 & 7,9 & 14,2 & 1 & 30 \\
\hline Juli/2017 & 8 & 25 & 5 & 6,5 & 15 & 1 & 31 \\
\hline Agustus/2017 & 4,1 & 25,1 & 4 & 8,3 & 16 & 0 & 31 \\
\hline September/2017 & 4,3 & 25,3 & 6 & 8,1 & 14,1 & 0 & 30 \\
\hline Oktober/2017 & 3 & 26 & 4,2 & 7 & 14 & 0 & 31 \\
\hline November/2017 & 8,2 & 26,5 & 3,9 & 5 & 14,6 & 1 & 30 \\
\hline Desember/2017 & 7 & 26,2 & 5 & 5,5 & 12 & 1 & 31 \\
\hline Januari/2018 & 9,6 & 29,8 & 4,2 & 6 & 15,6 & 1 & 30 \\
\hline Februari/2018 & 4 & 25 & 5,8 & 7,6 & 15,8 & 0 & 29 \\
\hline Maret/2018 & 3,6 & 26,6 & 6 & 6,2 & 17 & 0 & 31 \\
\hline April/2018 & 2 & 26 & 5 & 5,6 & 16,1 & 0 & 30 \\
\hline Mei/2018 & 3 & 27 & 4,2 & 5 & 15 & 0 & 31 \\
\hline Juni/2018 & 4,6 & 28,6 & 4,7 & 5,5 & 16 & 0 & 30 \\
\hline Juli/2018 & 3 & 26 & 4 & 4,5 & 16,3 & 0 & 31 \\
\hline Agustus/2018 & 2,8 & 25,8 & 4,9 & 5 & 16,5 & 0 & 31 \\
\hline September/2018 & 5,1 & 25,1 & 5,9 & 4,1 & 16 & 1 & 30 \\
\hline Oktober/2018 & 4 & 24 & 6 & 6 & 16,1 & 0 & 31 \\
\hline November/2018 & 6 & 26 & 5,9 & 6,6 & 14 & 1 & 30 \\
\hline Desember/2018 & 4 & 25 & 5 & 4 & 13 & 0 & 31 \\
\hline
\end{tabular}

